\title{
Tram LC Filter Stabilization by Energy Storage System
}

\author{
Luboš Streit ${ }^{1)}$, Jakub Talla ${ }^{2)}$ and Martin Janda ${ }^{3)}$ \\ 1) University of West Bohemia in Pilsen/RICE, Pilsen, Czech Republic, e-mail: lloyd@ rice.zcu.cz \\ 2) University of West Bohemia in Pilsen/RICE, Pilsen, Czech Republic, e-mail: talic@ @ice.zcu.cz \\ 3) University of West Bohemia in Pilsen/RICE, Pilsen, Czech Republic, e-mail: mapa@ rice.zcu.cz
}

\begin{abstract}
The paper is focused on the tram input LC traction filter stabilization by the Energy Storage System. The input $\mathrm{LC}$ filter is almost undamped resonant circuit which is mainly excited by the motor constant torque command. The tram during voltage drops increases the current flow from the $L C$ filter to hold constant torque and thereby further decreases the LC filter voltage, and vice versa. This could lead to unstable traction drive behaviour. The Energy Storage System can be used to stabilize LC filter voltage.
\end{abstract}

Keywords - tram, traction, filter stability, supercapacitor, energy storage system.

\section{INTRODUCTION}

This research is focused on the light traction vehicle (tram) drive LC filter stability. These vehicles are fed from a DC catenary of voltage around $600 \mathrm{~V}$. The LC filter must be present at the input of the vehicle due to satisfactory EMC and for correct operation of the voltage inverter.

The LC filter is usually damped by passive or active principles. The passive damping is easy to use but it decreases powertrain effectivity. Therefore, the input LC filter cannot have natural damping. On the other hand, the most of active solutions use kinetic energy of a motor with high moment of inertia as energy storage for active damping [1], [2]. This high moment of inertia decreases an impact to a mechanical damage of a gearbox. The motor moment of inertia is too low in light traction vehicles. Therefore, this active method is not so suitable for them and it can reduce service life of the tram.

The proposed method employs on-board energy storage system based on supercapacitors for active damping of the LC filter. The traction input LC filter stability is necessary for avoiding a damage of the traction vehicle electrical or mechanical equipment When the LC filter is not damped the overvoltage can destroy the dc link capacitor or switching devices. Therefore, trams use variety of overvoltage or undervoltage protections.

\section{TRAM EQUIPPED WITH ENERGy STORAGE SYSTEM}

Today topic in field of urban transport is energy efficiency. Vehicles of an urban transport increase its efficiency by employing of low power equipment, new converter topologies, modern power semiconductors, energy recuperation and kinetic energy storage. Energy Storage Systems (ESSs) can be divided in two groups: onboard and off-board. The main advantage of the off-board ESS is lower costs of installation due to the usage of them by all vehicles on the same part of a track. On the other hand, the main advantage of the on-board ESS is usage in the whole track line. This solution is especially suitable in a track line with low probability of consumption of the recuperated energy or with prohibited recuperation to the Overhead Line (OHL). The next advantage of the onboard ESS is running without OHL what is required in a city historical centre. The following text will suppose the on-board ESS. Main components of tram with the onboard ESS are shown in Fig. 1.

The ESS is controlled by the Power Management (PM). Strategies of the PM can be basic or advanced [3]. Basic strategies include proportional, mean power, peak shaving etc.

- Proportional PM strategy accumulates full recuperative energy and then covers tram power demand multiplied by proportional constant (less or equal to 1 ).

- Mean Power PM consumes the mean power from the OHL all time and the difference between this mean power and actual power demand/recuperation is covered by the ESS.

- Peak Shaving PM consumes the value of power from the OHL only up to an adjusted limit (peak level). The difference between the power demand and the peak limit is covered by the ESS. It means that the power peaks (from OHL) are shaved to the peak level. This PM decreases losses in OHL.

Advanced PMs use tram position at known track line, stochastic model of other trams, fuzzy controller [3] or other control methods such as dynamic programming [4], polynomial control strategy 0, [6], machine learning techniques [7] and neural networks [8].

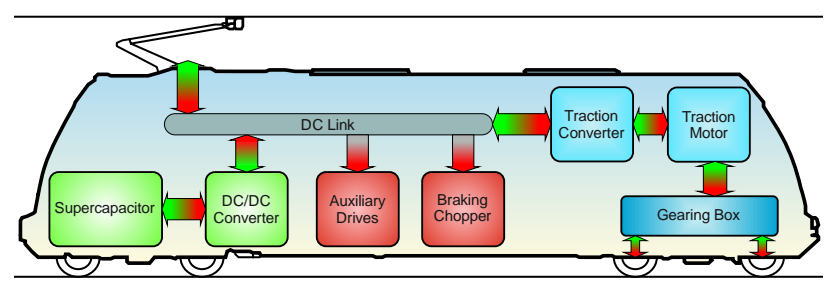

Fig. 1. Main components of tram with energy storage system.

\section{LC FILTER STABILITY}

Sources of the input LC filter oscillation may be present on the vehicle, typically drive control influence. From short time point of view, the drive is operated at approximately constant power when a constant torque is 
required at high moment of inertia (slow speed changes). Then the DC link voltage drop causes an increase in the traction current which causes another voltage drop, so positive feedback occurs in the system. Other sources of oscillations are low frequency harmonics presented in the current taken by traction inverter.

Sources of oscillations outside the vehicle are mainly the trolley voltage changes caused by fluctuations in power consumption and harmonics from surrounding vehicles, and temporary loss of catenary voltage caused by crossings of insulated sections or icing on catenary.

\section{A. Passive Methods of LC Filter Damping}

The simplest damping method is adding resistance in parallel to the input choke. The low-frequency component of the traction current passes mostly through the input choke, the energy of the high frequency components, means also a part of the traction current corresponding to the input filter LC oscillations, is wasted on the added resistor. The advantage of this method is simplicity and resulting robustness, the disadvantages are worse overall vehicle efficiency and higher vehicle weight.

Another theoretical option is to add a resistor in parallel to the input filter capacitor, which is flowed through by a DC current causing even greater losses than in the previous case.

\section{B. Active Methods of LC Filter Damping}

Simple active damping methods with better efficiency are based on the correction of the required torque depending on the instantaneous voltage value in the DC link, e.g. equations (1)-(3), [9], [10] and [11]:

$$
T_{W C}=\left(\frac{U_{C}}{U_{C \text { Filtered }}}\right)^{n} \cdot T_{W}
$$

Where $\mathrm{T}_{\mathrm{WC}}$ is the corrected value of the desired torque $\mathrm{T}_{\mathrm{W}}, \mathrm{U}_{\mathrm{C}}$ is instantaneous $\mathrm{DC}$ link voltage, $\mathrm{U}_{\mathrm{C} \text { Filtered }}$ is the low-pass filtered value of the DC link voltage and $\mathrm{K}$ is a gain.

$$
T_{W C}=K \cdot U_{C \text { Filtered }}+T_{W}
$$

Where $U_{C \text { Filtered }}$ is band-pass filtered value of the DC link voltage.

$$
T_{W C}=\frac{U_{C}}{U_{C \text { Filtered }}} \cdot T_{W}+K \cdot\left(U_{C}-U_{C \text { Filtered }}\right)
$$

Where $U_{C \text { Filtered }}$ is the low-pass filtered value of the DC link voltage.

More advanced methods of active oscillation damping use more information about the drive state for calculation the current component damping oscillations, injected by the drive into the DC link, e.g. [12], where corrections of the VSI desired voltage is calculated in dependence on the drive state, motor and input LC filters parameters, which unfortunately change with temperature and especially with catenary parameters and vehicle distance from traction substation.

The requirement for the input LC filter damping can be also directly part of the drive control algorithms as the method using FSC-MPC described in [13].

Main advantage of these methods is that they do not add extra HW components to the drive but still cause torque oscillations that are undesirable for the drive mechanical parts, especially the gearbox and the long shafts. Another disadvantage is the insufficient damping capability at low speeds where even large torque oscillations do not produce a sufficient current response for the LC filter damping.

\section{NOVEl METHOD OF LC FILTER DAMPING}

The proposed method of the LC filter damping employs the ESS with supercapacitors. Main feature of the ESS is energy balancing to decrease losses caused by a tram. An additional feature of the ESS in this case is supplying of LC filter stabilizer (active damping). Impact to the losses in ESS is minimal due to the low power demand for damping in comparison with power demand for traction effort. Mechanical parts, such as the gearing box, motor, bearings, are not negatively influenced due to the damping directly in the electric side.

\section{A. Priciple of LC Filter Damping}

The filter stabilizer damps oscillations in the input LC filter in the tram as was mentioned above. Damping is achieved via current of the ESS ( $\mathrm{I}_{\mathrm{ESS}}$ ), respectively via the ac damping component of this current. A topology of tram with the ESS is shown in Fig. 2. The current consumed from catenary Overhead Lines is designated as $\mathrm{I}_{\mathrm{OHL}}$, a current consumed by traction inverter is designated as $\mathrm{I}_{\mathrm{TI}}$.

The traction inverter block includes the braking resistor with chopper IGBT. It is the standard tram equipment which is engaged for wasting of redundancy energy. It also prevents overvoltage of the input filter capacity. The block of the ESS includes DC/DC converter, coil $\mathrm{L}_{\mathrm{SC}}$ and supercapacitor (SC).

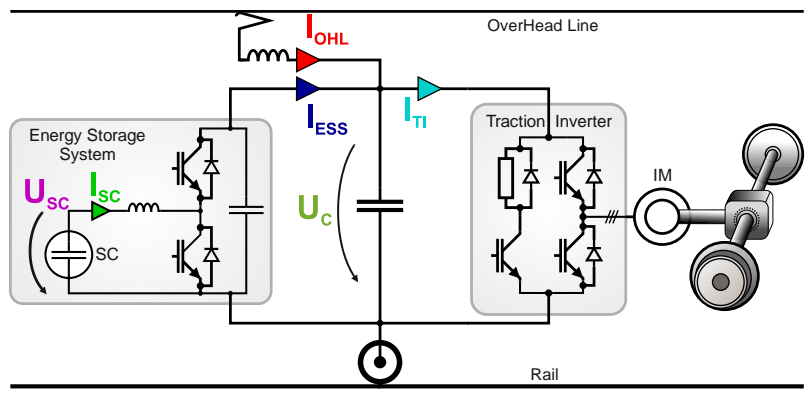

Fig. 2. Topology of tram with energy storage system.

The control of the ESS is composed of the power management (PM) and filter stabilizer (FS). The required current $\mathrm{I}^{*}$ ESS is a sum of currents $\mathrm{I}^{*}$ ESS FS and $\mathrm{I}^{*}$ ESS PM. This control is shown in Fig. 3. The required current $\mathrm{I}^{*} \mathrm{SC}$ is then calculated from equality of the ESS power and the SC power (excl. losses). Equation (4) shows the equality.

$$
I_{S C} \cdot U_{S C}=I_{E S S} \cdot U_{C}
$$

The standard PI controller is used for the ISC control. The output of the controller is the voltage of $\mathrm{L}_{\mathrm{SC}}$, due to direct coupling to the current rising/falling. For correct control output it is necessary to add the voltage $U_{S C}$ to achieve ihe required voltage of the DC/DC converter arm, which is than normalized by $\mathrm{U}_{\mathrm{C} \text { filtered. }} \mathrm{PWM}$ signals for ESS transistors are generated from this normalized value. 


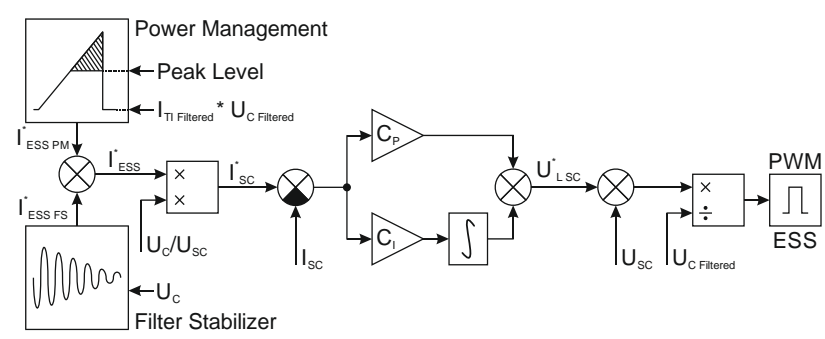

Fig. 3. Control of energy storage system with filter stability feature.

\section{B. Power Management}

The peak shaving PM is used in the simulation. The peak level is set to $300 \mathrm{~kW}$. This PM is chosen for its acceptable saving results, clear principle and easy implementation. The following Fig. 4. makes clear the peak shaving $\mathrm{PM}$. The value $\mathrm{P}_{\text {TRAM }}$ includes consumption of auxiliary drives, heating/air condition etc. This tram power is calculated simplified for needs of the simulation as (5) shows. The required current is then calculated from (6).

$$
\begin{gathered}
\mathrm{P}_{\text {TRAM }}=\mathrm{I}_{\mathrm{TI} \text { Filtered }} \cdot \mathrm{U}_{\mathrm{C} \text { Filtered }} \\
\mathrm{I}_{\mathrm{ESS} \text { PM }}^{*}=\frac{\mathrm{P}_{\mathrm{ESS}}^{*}}{\mathrm{U}_{\mathrm{C} \text { Filtered }}}
\end{gathered}
$$

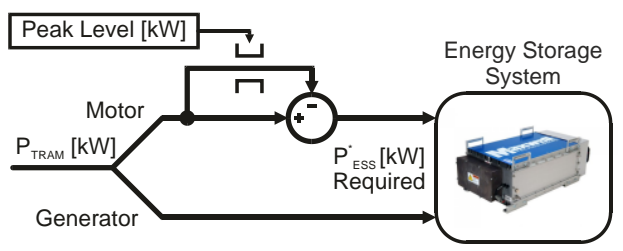

Fig. 4. Peak shaving power management.

\section{Filter Stabilizer}

The control of the filter stabilizer is described in Fig. 5. The required current is obtained by separating of an ac component of the tram input filter capacitor voltage $\mathrm{U}_{\mathrm{C}}$.

A role of the low pass filter is to pass changes of the OHL voltage level caused by varying loads (other trams) which are varying in time. A low pass filter cutoff frequency should be optimized for filtering of the tram input LC filter resonant frequency. The polarity of $\mathrm{U}_{\mathrm{Cac}}$ is negative due to a difference block. The $\mathrm{U}_{\mathrm{Cac}}$ is then multiplied by proportional controller.

This control generates the required current which is opposite to oscillating voltage $\mathrm{U}_{\mathrm{C}}$. In this way the oscillations are actively damped.

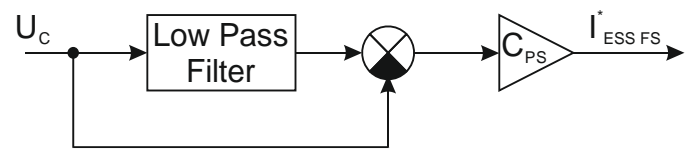

Fig. 5. Filter stabilizer control.

\section{SIMULATIONS}

\section{A. Simulation parameters}

The simulation model includes tram current behaviours measured on real tram LTM 10.08 also known as ASTRA made by Škoda Electric Company. It is a three-segment low-floor tram. The nominal continuous power is $340 \mathrm{~kW}$ and $500 \mathrm{~kW}$ in overload. This tram was not equipped with the on-board ESS.

The real tram was equipped with the standard damping of the LC filter. The measured current is used for power demand calculation (multiplication by measured voltage $\mathrm{U}_{\mathrm{C}}$ ). The simulation model uses the calculated power demand for back calculation of the traction inverter current $\mathrm{I}_{\mathrm{TI}}$ (dividing by simulated $\mathrm{U}_{\mathrm{C}}$ voltage). The back calculation brings to the model the positive feedback well known in traction vehicles with constant power demand (in short time point of view). This positive feedback invokes the unwanted input filter oscillation.

The traction inverter is modelled as a current source of the calculated $\mathrm{I}_{\mathrm{TI}}$. The braking chopper is excluded from the traction inverter. The chopper is switched by hysteretic controller ( $800 \mathrm{~V}$ on, $760 \mathrm{~V}$ off). The ESS is modelled as shown in Fig. 2. (capacitor, coil included inductance and resistance, two IGBTs). The input LC filter is composed of capacity and coil (resistance and inductance). The catenary is created by the voltage source $600 \mathrm{~V}$, resistance and inductance. A position of the simulated tram is $1 \mathrm{~km}$ far from a traction substation.

The energy capacity of the ESS is designed by respecting the economic analysis result in [14]. Using of three transportation SC modules $(125 \mathrm{~V} 63 \mathrm{~F}$ by Maxwell Company) seems to be optimum for return on the investment. The final SC capacity is $21 \mathrm{~F}$ and voltage range $188 \mathrm{~V}$ to $375 \mathrm{~V}$. Inductance of the coil in the ESS is $1 \mathrm{mH}$ and resistance is $5 \mathrm{~m} \Omega$.

The inductance of the OHL is $1 \mathrm{mH}$ and resistance is $122 \mathrm{~m} \Omega$. It corresponds to $1 \mathrm{~km}$ of the OHL wire of $150 \mathrm{~mm}^{2}$ cross section. The input LC filter has capacity $8 \mathrm{mF}$, coil parameters are $1 \mathrm{mH}$ and $40 \mathrm{~m} \Omega$ (resistance at $\left.165^{\circ} \mathrm{C}\right)$.

A resistance of the braking resistor is $500 \mathrm{~m} \Omega$ and a parasitic inductance is $100 \mu \mathrm{H}$. When the voltage on the input filter capacitor $U_{C}$ exceeds level of $800 \mathrm{~V}$ the chopper IGBT will turn on. The IGBT is still on until the voltage decreases above $760 \mathrm{~V}$.

Simulation results of three different cases are described in the following chapter. The first one is simulation of the tram which is not equipped with any (standard) damping system. The ESS is deactivated in this case. Behaviours are shown in Fig. 6. The second case is simulation of a tram with the activated ESS, but still without any damping system. The Fig. 7. shows its results. The third case is simulation with the activated ESS and Filter Stabilizer. The results of the proposed method are shown in Fig. 8. 


\section{B. Simulation Results}

In case of an undamped LC filter the unwanted oscillation occurs, which is visible in Fig. 6. The overvoltage of $\mathrm{U}_{\mathrm{C}}$ is shaved only by braking the chopper at $800 \mathrm{~V}$. The oscillation also creates undervoltage. A standard undervoltage protection should cut off the power demand in real tram operation. The undervoltage level is usually about $500 \mathrm{~V}$. The undervoltage protection is not used for better visibility of oscillation during whole tested period.

The oscillation is poorly decreased in case of a tram with the ESS, which is shown in Fig. 7. Peaks of oscillation are decreased, but it is not sufficient. The powertrain is still unstable and non-operable. The ESS tries to cover peak power higher than $300 \mathrm{~kW}$. It is visible in $\mathrm{I}_{\mathrm{SC}}$ or $\mathrm{U}_{\mathrm{SC}}$ respectively. During tram braking the kinetic energy is accumulated into the Supercapacitor. The energy is accumulated until the Supercapacitor voltage $U_{S C}$ reaches the maximum level of $375 \mathrm{~V}$.

Behaviour of the proposed method is shown in Fig. 8. The designed filter stabilizer is able to suppress the oscillations, what is visible in all values. The peak shaving $\mathrm{PM}$ of the ESS is now more visible due to the oscillation missing. An overshooting in $\mathrm{U}_{\mathrm{C}}$ occurs when the ESS stopped the accumulating, because the maximal Supercapacitor voltage is reached.
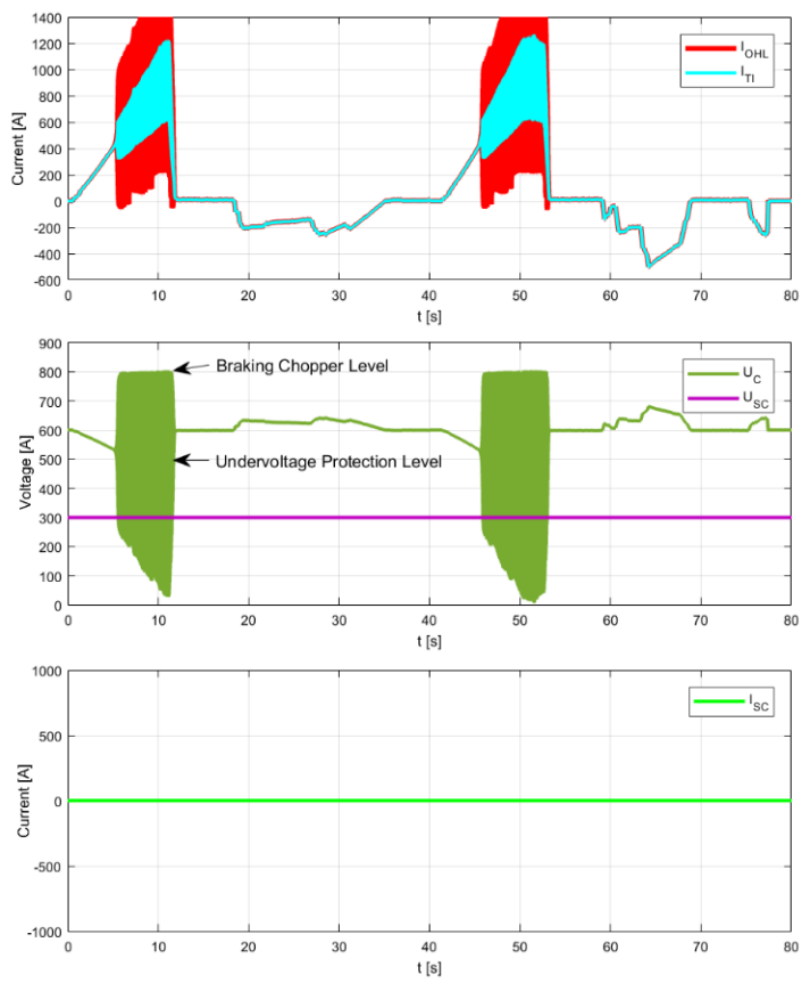

Fig. 6. Behaviours of tram without ESS and without filter stabilizer.
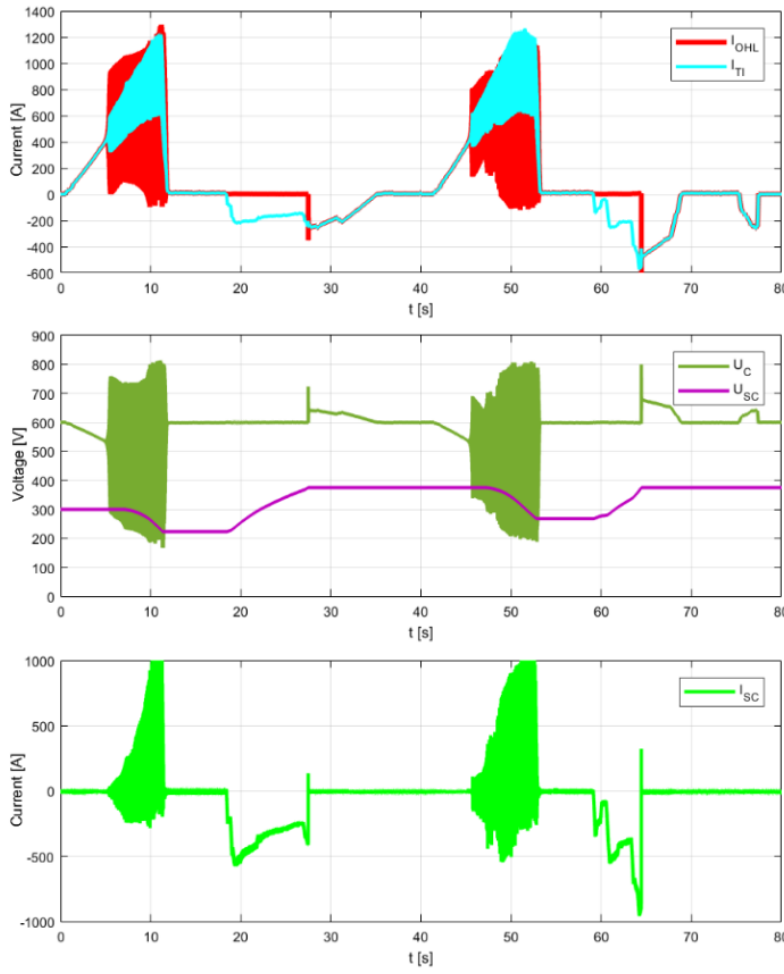

Fig. 7. Behaviours of tram with ESS and without filter stabilizer.
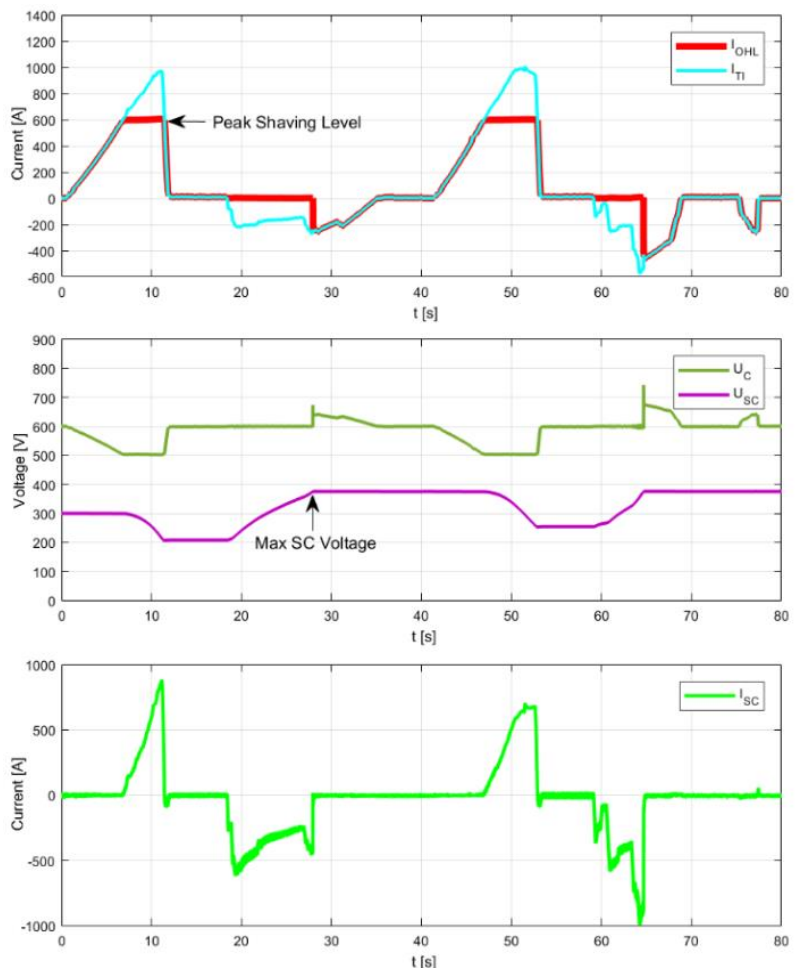

Fig. 8. Behaviours of tram with ESS and with filter stabilizer. 


\section{CONCLUSION}

The proposed method of the tram input LC filter active damping is able to stabilize the catenary DC link voltage. It is also very profitable for increasing whole catenary system stability and reliability.

The main advantage of the proposed filter stabilizer is active damping without negative impact upon the mechanical parts. It contributes to the reliability of the tram operation. Losses of the stabilizer (due to the adding of the ac current component to the existing ESS output current) are low in comparison to the passive damping.

However, presented stabilizer is usable only for trams equipped with the ESS. This paper supposes supercapacitor as an energy storage device. Nevertheless, the energy storage with any other storing devices (such as flywheel, battery, etc.) is employable.

\section{ACKNOWLEDGMENT}

This research has been supported by the Ministry of Education, Youth and Sports of the Czech Republic under the RICE - New Technologies and Concepts for Smart Industrial Systems, project No. LO1607. and project No. SGS-2018-009.

\section{REFERENCES}

[1] T. Glasberger, J. Talla, M. Janda, Z. Peroutka, and V. Smidl, "DTC controlled PMSM traction drive input LC filter stabilization using model predictive control," in 2012 15th International Power Electronics and Motion Control Conference (EPE/PEMC), Novi Sad, 2012, pp. DS1e.4-1-DS1e.4-7. doi: 10.1109/EPEPEMC.2012.6397244

[2] T. Glasberger, M. Janda, V. Muzikova, J. Majorszky, and Z. Peroutka, "Frequency analysis and stability enhancement of DTC controlled PMSM drive with input LC filter," in 2012 Electrical Systems for Aircraft, Railway and Ship Propulsion, Bologna, 2012, pp. 1-6. doi: 10.1109/ESARS.2012.6387413

[3] J. Talla, L. Streit, Z. Peroutka, and P. Drabek, "Position-Based TS Fuzzy Power Management for Tram With Energy Storage System," IEEE Transactions on Industrial Electronics, vol. 62, no. 5, pp. 3061-3071, May 2015. doi: 10.1109/TIE.2015.2396871

[4] E. Bilbao, P. Barrade, I. Etxeberria-Otadui, A. Rufer, S. Luri, and I. Gil, "Optimal Energy Management Strategy of an Improved Elevator With Energy Storage Capacity Based on Dynamic Programming," IEEE Trans. Ind. Applications, vol. 50, no. 2, pp. 1233-1244, April 2014. doi: 10.1109/TIA.2013.2276015
[5] M.B. Camara, H. Gualous, F. Gustin, A. Berthon, and B. Dakyo, "DC/DC Converter Design for Supercapacitor and Battery Power Management in Hybrid Vehicle Applications-Polynomial Control Strategy," IEEE Trans. Ind. Electron., vol. 57, no. 2, pp. 587-597, Feb. 2010. doi: 10.1109/TIE.2009.2025283

[6] H.K. Lam and Hongyi Li, "Output-Feedback Tracking Control for Polynomial Fuzzy-Model-Based Control Systems," IEEE Trans. Ind. Electron., vol. 60, no. 12, pp. 5830-5840, Dec. 2013. doi: 10.1109/TIE.2012.2229679

[7] Ch. Zhihang, M.A. Masrur, and Y.L. Murphey, "Intelligent vehicle power management using machine learning and fuzzy logic," in IEEE Conf. Fuzzy Systems. FUZZ-IEEE 2008. (World Congress on Computational Intelligence), pp.2351-2358, June 2008.

[8] C. Abbey, K. Strunz, and G. Joos, "A Knowledge-Based Approach for Control of Two-Level Energy Storage for Wind Energy Systems," IEEE Trans. on Energy Conversion, vol. 24, no. 2, pp. 539-547, June 2009 doi: 10.1109/TEC.2008.2001453

[9] S. D. Sudhoff, K. A. Corzine, S. F. Glover, H. J. Hegner, and H. N. Robey, Jr., "DC link stabilized field oriented control of electric propulsion systems," IEEE Trans. Energy Convers., vol. 13, no. 1, pp. 27-33, Mar. 1998. doi: $10.1109 / 60.658200$

[10] H. Mosskull, "Some issues on stabilization of an induction machine drive," in Proc. 43rd IEEE Conf. Decision and Control, The Bahamas, 2004, pp. 4441-4446. doi: 10.1109/CDC.2004.1429450

[11] K. Pietiläinen, L. Harnefors, A. Petersson, and H.-P. Nee, "DClink stabilization and voltage sag ride-through of inverter drives," IEEE Trans. Ind. Electron., vol. 53, no. 4, pp. 1261-1268, Aug. 2006.

doi: 10.1109/TIE.2006.878308

[12] N. Zhao, G. Wang, D. Xu, and D. Xiao, "An Active Damping Control Method for Reduced DC-Link Capacitance IPMSM Drives," IEEE Transactions on Industrial Electronics, vol. 65, no. 3, pp. 2057-2068, March 2018. doi: 10.1109/TIE.2017.2748062

[13] V. Šmídl, Š. Janouš, and Z. Peroutka, "Improved Stability of DC Catenary Fed Traction Drives Using Two-Stage Predictive Control," IEEE Transactions on Industrial Electronics, vol. 62, no. 5, pp. 3192-3201, May 2015 doi: $10.1109 /$ TIE.2015.2392718

[14] L. Streit, J. Talla, and P. Drabek, "Economic comparison of basic energy storage system control strategies," in Proceedings of the 16th International Conference on Mechatronics - Mechatronika 2014, Brno, 2014, pp. 662-665. doi: 10.1109/MECHATRONIKA.2014.7018339 